\title{
SIRKUIT HAMILTON DALAM PERMAINAN CONGKLAK
}

\author{
Rukmono Budi Utomo ${ }^{\mathrm{a}}$ \\ ${ }^{\text {a }}$ Program Studi Pendidikan Matematika FKIP UMT \\ Jl. Perintis Kemerdekaan I No 33, Cikokol Kota Tangerang, Provinsi Banten \\ rukmono.budi.u@mail.ugm.ac.id
}

\begin{abstract}
ABSTRAK
Penelitian ini dilakukan untuk menyelidiki adanya kemungkinan sirkuit Hamilton pada permainan congklak 14 dan 16 lubang. Penelitian dilakukan dengan mendeskripsikan terlebih dahulu mengenai permainan congklak, aturan-aturan dalam permainan congklak, istilah-istilah dalam permainan congklak dan cara memainkannya. Setelah memahami aturan, istilah dan cara memainkan permainan congklak, selanjutnya dilakukan penyelidikan untuk menemukan kemungkinan adanya siklus Hamilton pada permainan congklak 14 dan 16 lubang tersebut. Sirkuit Hamilton dalam permainan congklak diartikan sebagai perjalanan menyebarkan biji congklak pada suatu lubang dan habis pada lubang yang sama pada suatu kesempatan permainan. Dalam penelitian ini, disajikan contoh perjalanan biji congklak yang menghasilkan siklus Hamilton untuk congklak dengan 14 lubang, dan bentuk umum permainan congklak yang menghasilkan sirkuit Hamilton untuk congklak dengan 16 lubang.
\end{abstract}

Kata Kunci : Permainan Congklak Sirkuit Hamilton

\begin{abstract}
This research was conducted to investigate possibility of Hamiltonian circuit on the 14 and 16 holes congklak games. Research carried out by describing the advance of the congklak game, rules and terms on the congklak game and how to play it. After that, we investigate possibility to find Hamiltonian circuit on the 14 and 16 holes congklak games. Hamltonian circuit on the congklak game meaning traveling to spreading seeds on a hole on the congklak game and stopping on that hole it self in the one chance playing. In this research we deliver an example travelling to spreading seeds that producing Hamilton circuit both 14 and 16 holes congklak games.
\end{abstract}

\section{Keywords: Congklak Games, Hamilton Circuit}




\section{Pendahuluan}

Congklak merupakan nama sebuah permainan tradisional yang terkenal di Indonesia. Permainanan ini banyak ditemukan di Jawa, Lampung, Sulawesi serta beberapa daerah melayu seperti Riau dan Sumatera Selatan. Tidak hanya di Indonesia, permainan congklak ini juga dapat ditemukan Malaysia, Brunai Darussalam dan Singapura. Di beberapa daerah, permainan congklak dikenal dengan nama dakon, dhakon, dhakonan, dentuman lamban dan mokaotan. Dalam bahasa inggris, permainan congklak ini disebut dengan Mancala.

Congklak merupakan sebuah permainan berbentuk papan yang memiliki 16 lubang dan biasanya terbuat dari kayu atau plastik. Lubang-lubang dalam congklak terdiri atas 14 lubang kecil dan 2 lubang besar yang disebut sebagai lubang induk. Masing-masing lubang kecil terdiri atas 7 biji congklak dan biji-biji tersebut akan disebarkan ke semua lubang kecuali pada lubang induk milik lawan.

Permainan ini dilakukan secara berpasangan dengan setiap pemain memperoleh 7 lubang kecil yang berada tepat di depannnya dan 1 lubang induk yang berada di sebelah kiri pemain tersebut. Jumlah lubang dalam permainan congkak ini dapat bervariasai. Di beberapa daerah di Indonesia terdapat pula congklak dengan 14 lubang yang terdiri dari 12 lubang kecil dan 2 lubang induk

Dalam permainan congklak didefinisikan beberapa istilah yang berlaku dalam permainan ini. Istilahistilah tersebut dibagi atas Satu Jalan, Dua Jalan dan Iterasi. Istilah Satu Jalan memberi arti bahwa pemain mengambil seluruh biji pada suatu lubang kecil miliknya dan disebarkan ke semua lubang yang lain kecuali lubang induk milik lawan. Proses ini hanya dilakukan satu kali sampai pemain tersebut tidak dapat melakukan penyebaran biji lagi dikarenakan biji congklak terakhir yang diambilnya jatuh pada lubang kosong yang tidak terisi minimal satu biji congklak yang mendiami lubang tersebut sebelumnya. Apabila biji terakhir jatuh pada lubang kecil miliknya dan terdapat biji congklak pada lubang kecil milik lawan yang berada tepat di depan lubang tempat biji terakhir itu jatuh, maka pemain tersebut dapat mengambil semua biji congklak di lubang yang bersangkutan dan biji congklak pada lubang milik lawan yang berada didepannya untuk ditaruh pada lubang besar milik pemain tersebut. Hal ini disebut sebagai Nembak.

Lebih lanjut apabila biji terakhir jatuh pada lubang kecil miliknya sendiri 
atau lubang kecil milik lawan dan tidak ada minimal satu biji congklak yang mendiami lubang tersebut, maka pemain tersebut harus berhenti dan giliran bermain berganti pada pemain lainnnya.

Pengembangan dari istilah Satu Jalan adalah Dua Jalan. Istilah Dua Jalan ini identik dengan ungkapan lain yang serupa misalnya Tiga Jalan, Empat Jalan dan seterusnya. Istilah Dua Jalan menyatakan proses kelanjutan dari satu jalan yakni apabila biji terakhir yang dijalankan jatuh pada lubang kecil yang memiliki sekurang-kurangnya 1 biji congklak yang mendiami lubang tersebut sebelumnya.

Apabila biji terakhir jatuh pada lubang besar, maka pemain yang bersangkutan masih dapat melanjutkan giliran bermainnya dengan memilih lubang manapun miliknya yang ia sukai untuk dilakukan penyebaran biji congklak kembali. Proses jatuhnya biji pada lubang besar sehingga pemain masih dapat melanjutkan permainannya dan memilih biji pada lubang manapun miliknya untuk melanjutkan proses penyebaran biji congklak disebut sebagai Satu Iterasi. Dari istilah Satu Iterasi ini dapat dikembangkan istilah serupa Dua Iterasi, Tiga Iterasi dan lainnya.

Semua proses penyebaran biji congklak dilakukan dengan arah sejalan dengan jarum jam. Pemenang dari permainan congklak ini ditentukan dari banyaknya biji congklak yang terkumpul pada lubang induk. Pemain yang mengumpulkan biji congklak terbanyak pada lubang induk miliknya dianggap sebagai pemenang.

Dalam Teori Graf, terdapat pembahasan mengenai Lintasan dan Sirkuit Hamilton. Pembahasan kedua konsep ini dimulai dengan mengenalkan terlebih dahulu definisi dari Graf itu sendiri.

\section{Definisi Graf}

Graf adalah sekumpulan simpul atau titik (Vertex) yang dihubungkan satu sama lain melalui sisi atau busur (Edge).

Simpul adalah objek sembarang yang dapat dijabarkan, sedangkan busur adalah relasi yang menghubungkan antar objekobjek tersebut. Berdasarkan definisi Graf di atas, secara umum sebuah graf dapat dirumuskan dengan $G$ yang menyatakan Graf, Vertex $v$ untuk simpul dan Edges $e$ untuk menyatakan sisi atau busur dari Graf. Berdasarkan arah sisinya, Graf dibagi atas dua, yakni Graf Berarah (Directed Graph) dan Graf tidak berarah (Undirected Graph).

\section{Definisi Graf Berarah}

Graf berarah $G$ adalah Graf yang setiap setiap sisinya memiliki arah. 
Berdasarkan hal tersebut sisi dari titik $v_{1}$ ke $v_{2}$ tidaklah sama dengan sisi sebaliknya atau $\left\langle v_{1}, v_{2}\right\rangle \neq\left\langle v_{2}, v_{1}\right\rangle$.

\section{Definisi Graf Tidak Berarah}

Graf tidak berarah adalah Graf yang setiap setiap sisinya tidak memiliki arah.

Berdasarkan hal demikian sisi dari titik $v_{1}$ ke $v_{2}$ sama dengan sisi sebaliknya atau secara matematis dapat ditulis $\left\langle v_{1}, v_{2}\right\rangle=\left\langle v_{2}, v_{1}\right\rangle$.

Selain definisi dari Graf, Graf berarah dan Graf tidak berarah, perlu pula dikenalkan terminologi dasar dari Graf meliputi Bertetangga (Adjacent), Bersisisan (Incident), Derajat (Degrree) dari suatu Graf, dan Lintasan (Path).

\section{Definisi Bertetangga}

Dua buah simpul dari Graf tidak berarah $G$ dikatakan bertetangga apabila keduanya terhubung langsung dengan sebuah sisi.

\section{Definisi Bersisian}

Suatu sisi e dikatakan bersisian dengan simpul $v_{i}$ dan $v_{j}$ apabila $e=\left\langle v_{i}, v_{j}\right\rangle$ atau dengan kata lain e menghubungkan simpul $v_{i}$ dan $v_{j}$.

\section{Definisi Lintasan}

Lintasan adalah barisan berselang-seling simpul-simpul dan sisi-sisi yang berbentuk $v_{0}, e_{1}, v_{1}, e_{2}, \ldots, v_{n-1}, e_{n}, v_{n}$ yang mengumpulkan simpul awal $v_{0}$ dan simpul tujuan $v_{n}$.

Untuk graf sederhana, biasanya lintasan lintasan cukup ditulis sebagai baisan simpul-simpulnya saja yakni $v_{0}, v_{1}, \ldots, v_{n-1}, v_{n}$.

Lebih lanjut Graf dapat dikelompokkan menjadi beberapa jenis bergantung pada sudut pandang pengelompokkannya. Pengelompokkan Graf dapat dipandang berdasarkan ada atau tidaknya sisi ganda, berdasarkan jumlah simpul, atau berdasarkan orientasi arah dan sisi. Berdasarkan ada atau tidaknya sisi ganda pada suatu Graf, maka secara umum Graf dapat digolongkan menjadi 2 jenis, yakni Graf sederhana dan Graf tidak sederhana.

\section{Definsi Graf Sederhana}

Suatu Graf $G$ dikatakan sebagai Graf sederhana apabila tidak memuat sisi ganda atau gelang

\section{Definsi Graf Tidak Sederhana}

Suatu Graf $G$ dikatakan sebagai Graf tidak sederhana apabila memuat sisi ganda atau gelang.

Setelah Memahami definisi dari Graf beserta jenis-jenis Graf, maka selanjunta didefinisikan mengenai Lintasan 
Hamilton, Sirkuit Hamilton dan Graf Hamilton serta Graf Semi Hamilton.

Definsi Lintasan Hmilton

Lintasan Hamilton adalah lintasan yang melalui tiap simpul di dalam suatu Graf tepat satu kali.

\section{Definis Sirkuit Hamilton}

Sirkuit Hamilton adalah sirkuit yang melalui tiap simpul dalam suatu Graf tepat satu kali kecuali pada simpul asal sekaligus simpul akhir yang dilalui dua kali.

Graf $G$ yang memiliki sirkuit Hamilton disebut Graf Hamilton, sedangkan Graf $G$ yang hanya memiliki lintasan Hamilton disebut dengan Graf semi Hamilton.

Beberapa teorema yang berlaku pada Graf antara lain dijelaskan sebagai berikut.

\section{Teorema 1}

Syarat cukup agar Graf sederhana $G$ dengan $n>3$ buah simpul adalah Graf Hamilton apabila derajat tiap simpul paling sedikit $\frac{n}{2}$ atau $d(v) \geq \frac{n}{2}$.

\section{Teorema 2}

Setiap Graf Lengkap adalah Graf Hamilton

\section{Teorema 3}

Dalam Graf lengkap $G$ dengan $n>3$ buah simpul terdapat $\frac{(n-1) !}{2}$ sirkuit Hamilton

\section{Teorema 4}

Dalam Graf Lengkap $G$ dengan $n>3$ buah simpul dan $n$ ganjil terdapat ${ }^{(n-1) !} / 2$ sirkuit Hamilton yang saling lepas. Apabila $n$ genap dengan $n>4$, maka di dalam Graf Lengkap $G$ tersebut terdapat $(n-2) ! / 2$ sirkuit Hamilton yang saling lepas.

\section{Metode Penelitian}

Metode pada penelitian kali ini dimulai dengan memahami terlebih dahulu tentang pengertian permainan congklak, istilah-istilah dalam permainan congklak dan aturan-aturan yang berlaku dalam permainan congklak. Sebagaimana telah dijelaskan, papan congklak standar memiliki 16 lubang yang terdiri dari 14 lubang kecil dan 2 lubang besar. Masingmasing pemain akan mendapatkan 7 lubang kecil dan 1 lubang besar dengan tiap lubang kecil berisikan 7 biji congklak. Pemain diharuskan menjalankan biji dalam suatu lubang congklak ke setiap lubang kecuali pada 1 lubang induk milik lawan. Pemain dikatakan memenangkan permainan ini apabila mendapatkan biji congklak yang lebih banyak pada lubang induk

Istilah-istilah yang berlaku dalam permainan congklak sebagaimana di jelaskan di awal yakni dibagi atas Satu Jalan, Dua Jalan, dan Iterasi. Satu Jalan diartikan sebagai proses pengambilan 1 
kali biji-biji congklak dalam suatu lubang untuk disebarkan ke masing-masing lubang pada papan congkak (kecuali lubang induk lawan) sampai biji tersebut habis sehingga pemain yang bersangkutan tidak dapat melanjutkan permainannya dan gilirannya digantikan pemain lain.

Dua Jalan merupakan pengembangan dari istilah Satu Jalan yakni apabila biji terakhir yang disebarkan ke semua lubang kecuali lubang induk milik lawan, jatuh pada lubang yang memiliki sekurang-kurangnya 1 biji congklak yang mendiami lubang tersebut sebelumnya. Lebih lanjut istilah Iterasi diartikan apabila biji congkak terakhir yang disebarkan jatuh pada lubang Induk sehingga pemain yang bersangkutan masih dapat menjalankan gilirannya dengan memilih biji congklak pada lubang manapun miliknya.

Setelah memahami aturan, cara dan istilah permainan congklak, selnjutnya dilakukan pencarian jalan penyebaran biji congklak yang menghasilkan Sirkuit Hamilton. Pemahaman tentang Graf, lintasan dan sirkuit Hamilton telah dipahami dengan baik oleh peneliti sewaktu kuliah S1 dahulu.

Pencarian jalan pada permainan congklak yang menghasilkan sirkuit Hamilton akan dilakukan untuk congklak dengan 14 dan 16 lubang. Hal ini didasari karena dibeberapa daerah banyaknya lubang pada congklak bervariasi antar 14 dan 16 lubang. Setelah mencari jalan pada permainan congklak yang menghasilkan sirkuit Hamilton, selanjutnya dicoba menentukan bentuk umum dari permainan congklak yang menghasilkan Sirkuit Hamilton.

\section{Hasil dan Pembahasan}

Dalam pembahasan kali ini, penulis akan membahas pencarian jalan pada permainan congklak yang menghasilkan sirkuit Hamilton. Pembahasan ini dimulai dengan congklak dengan 14 lubang, kemudian setelahnya dilakukan pembahasan untuk congklak dengan 16 lubang. Berikut gambar congklak dengan 14 lubang.

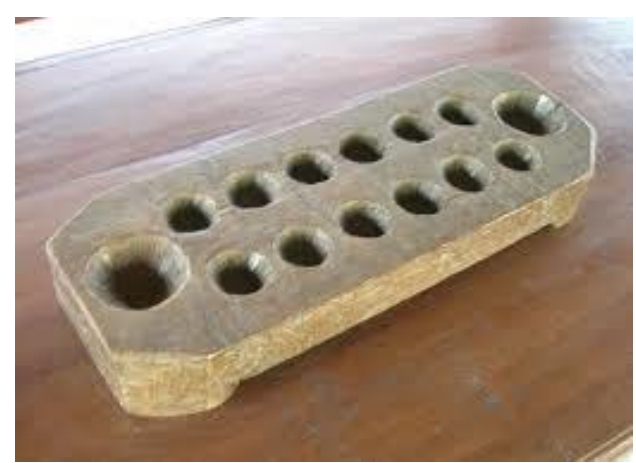

Gambar 1. Congklak 14 Lubang

Pada gambar 1 di atas terlihat bahwa congklak 14 lubang terbagi atas 12 lubang kecil dan 2 lubang induk. Masing-masing pemain akan mendapatkan 7 lubang kecil dan 1 lubang besar yang berada pada sebelah kirinya. Masing-masing lubang 
kecil tersebut berisikan 7 biji congklak yang harus disebarkan ke setiap lubang kecuali lubang induk milik lawan. Penyebaran biji congklak ini dilakukan searah jarum jam. Mekanisme penyebaran biji congklak dapat memperhatikan gambar berikut ini

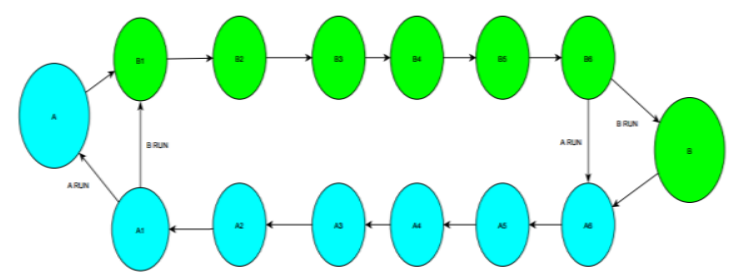

Gambar 2. Mekanisme permainan congklak

Pada gambar 2 di atas pemain $\mathrm{A}$ memperoleh 7 lubang congkak yang ditandai dengan warna hijau yang terdiri dari 6 lubang kecil dan 1 lubang induk.

Ketika pemain A tersebut memperoleh giliran menyebarkan biji pada suatu lubang congkak, maka penyebarannya tersebut dilakukan searah jarum jam dengan menyertakan lubang induk miliknya. Lebih lanjut pemain B memperoleh jumlah lubang yang sama dan ditandai dengan warna biru. Proses penyebaran biji congklak pada pemain B dilakukan searah jarum jam dengan menyertakan lubang induk miliknya dan melewatkan lubang induk lawan. Mekanisme ini dapat dilihat dari arah panah gambar 2
Untuk keperluan penyelidikan langkah dalam congklak yang menghasilkan siklus Hamilton, maka setiap lubang dalam congklak perlu diberi nama sesuai dengan kepemilikan pemain. Lubang-lubang kecil milik pemain A diberi nama $A_{1}, A_{2}, \ldots, A_{6}$ dan lubang induk miliknya diberi nama lubang induk $A$.

Lebih lanjut lubang-lubang kecil milik pemain $\mathrm{B}$ dibari nama $B_{1}, B_{2}, \ldots, B_{6}$ dan lubang induk miliknya diberi nama lubang induk $B$. Untuk lebih jelasnya dapat diperhatikan gambar 3 berikut ini.

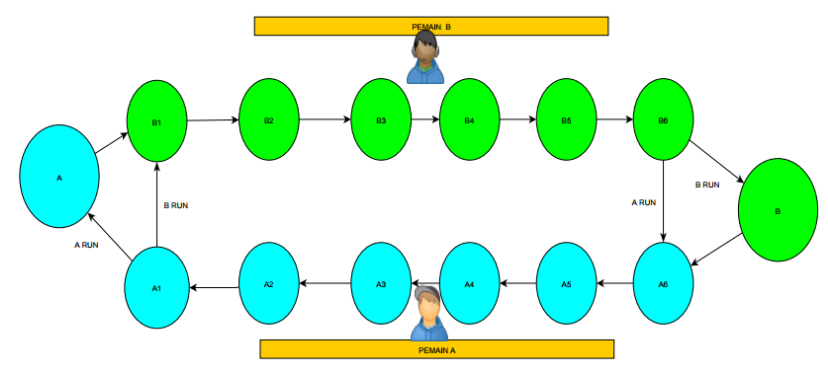

Gambar 3. Nama Pada Lubang Congklak

Pada gambar 3 di atas, lubanglubang dalam papan congklak telah diberi nama sesuai kepemilikan dari pemain A dan B. Lebih lanjut dalam penelitian kali ini akan dtentukan perjalanan menyebarkan biji congklak yang menghasilkan sirkuit Hamilton.

Misalkan permainan dilakukan pertama kali oleh pemain A. Pemain A berhak memilih satu dari enam lubang kecil miliknya Misalkan dalam kesempatan ini pemain $\mathrm{A}$ tersebut memilih lubang $A_{4}$. 
Lubang $A_{4}$ yang berisikan 7 biji congkak disebarkan ke lubang yang lain searah jarum jam kecuali pada lubang induk milik pemain B. Biji terakhir yang diambil pada lubang $A_{4}$ akan habis pada lubang $B_{3}$ sehingga biji pada lubang $B_{3}$ tersebut akan menjadi berjumlah 8 biji.

Lubang-lubang lain yang dilewati dari penyebaran biji yang diambi dari lubang $A_{4}$ seperti $A_{1}, A_{2}, A_{3}$ dan $B_{1} \operatorname{serta} B_{2}$ juga akan berisikan 8 biji dikarenakan penambahan 1 biji congklak yang diambil pada lubang $A_{4}$ tersebut. Proses penyebaran biji dari lubang $A_{4}$ sehingga biji habis pada lubang $B_{3}$ disebut Satu Jalan.

Lebih lanjut karena biji congklak yang disebar dari lubang $A_{4}$ dan habis pada lubang $B_{3}$ dengan kondisi lubang $B_{3}$ memuat sekurang-kurangnya 1 biji congklak yang mendiami sebeumnya, maka permainan dilanjutkan. Penyebaran biji dilakukan dilakukan dari lubang $B_{3}$ dan habis pada lubang $A_{2}$. Proses ini disebut dengan Dua Jalan. Dengan adanya penambahan biji congklak dari lubang $B_{3}$, maka kini lubang $A_{2}$ berisikan 9 biji congklak. Proses penyebaran biji congklak dari lubang $A_{2}$ sehingga habis pada lubang $A_{6}$ disebut Tiga Jalan.

Proses dilakukan kembali sehingga biji congklak dari lubang $A_{6}$ yang berjumlah 9 sehingga habis pada lubang $B_{3}$. Dengan adanya penambahan biji dari penyebaran pada lubang $A_{6}$, kini lubang $B_{3}$ memiliki 2 biji. Proses ini disebut dengan Empat Jalan. Permainan dilakukan kembali sehingga biji yang disebarkan dari lubang $B_{3}$ akan habis pada lubang $B_{5}$, sehingga lubang $B_{5}$ kini berisikan 10 biji congklak. Langkah ini disebut Lima Jalan.

Selanjutnya penyebabaran biji dari lubang $B_{5}$ akan habis pada lubang $B_{2}$, sehingga lubang $B_{2}$ kini berisikan 11 biji. Langkah ini diebut Enam Jalan. Perhatikan bahwa penyebaran biji dari lubang $B_{2}$ akan habis pada lubang induk milik pemain $\mathrm{A}$, sehingga pada langkah Tujuh Jalan terjadi Iterasi I. Berdasarkan hal tersebut, pemain A bebas memilih lubang manaupun untuk melanjutkan permainannya.

Misalkan pada kesempatan ke dua ini pemain $\mathrm{A}$ memilih lubang $A_{2}$ yang berisikan 3 buah biji congklak untuk disebarkan pada semua lubang lain dalam congklak. Penyebaran biji dari lubang $A_{2}$ akan habis pada lubang $B_{1}$ sehingga kini 
lubang $B_{1}$ berisikan 12 biji. Langkah ini disebut Delapan Jalan. Perhatikan bahwa penyebaran biji dari lubang $B_{1}$ pada langkah Sembilan Jalan akan habis pada lubang induk A, sehingga terjadi Iterasi II. Dengan demikian Pemain A berhak memiih lubang untuk meneruskan permainannya.

Misalkan pada kesempatan III ini pemain A memilih lubang $A_{3}$ yang berisikan 13 biji congklak. Penyebaran biji congklak dari lubang $A_{3}$ ini akan habis pada lubang $A_{3}$ kembali dan terjadilah Sirkuit Hamilton pada perjalanan ke Sepuluh Jalan.

Untuk lebih memahami kejadian Sirkut Hamilton pada Sepuluh Jalan yakni ketika biji yang diambil pada lubang $A_{3}$ habis di lubang yang sama yakni lubang $A_{3}$ dapat memperhatikan gambar 4 sebagai berikut

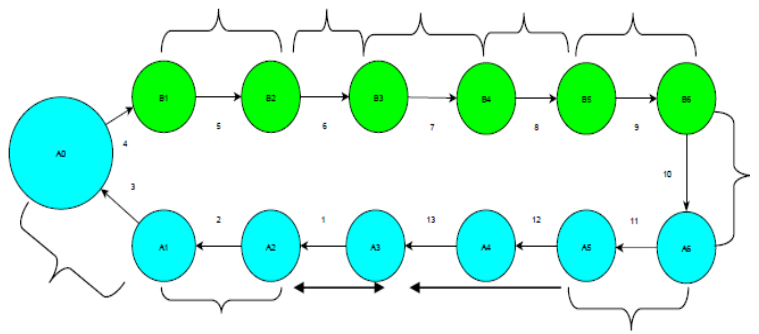

Gambar 4. Sirkuit Hamilton Pada lubang $A_{3}$

Dalam gambar 4 di atas terlihat bahwa sirkuit Hamilton terjadi pada iterasi ke II dalam langkah sepuluh jalan yakni ketika pengambilan biji pada lubang $A_{3}$ habis di lubang yang sama tanpa ada minimal 1 biji yang mendiami lubang $A_{3}$ sebelumnya. Pehitungan langkah dalam mencari siklus Hamilton ini disajikan dalam tabel sebagai berikut.

Tabel 1. Perhitungan langkah permainan conglak yang menghasilkan siklus Hamilton

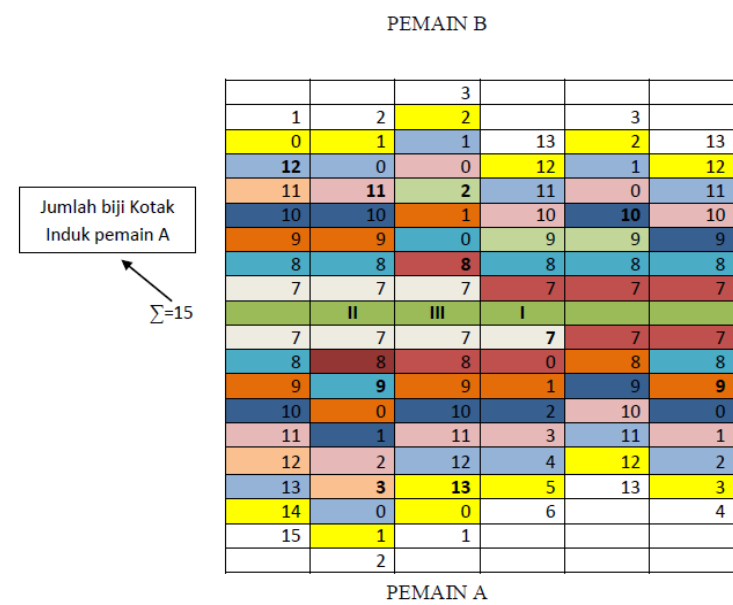

Dari Tabel 1 di atas, terlihat bahwa penyebaran biji congklak tiap Jalan atau Langkah diberi warna yang sama. Sirkuit Hamilton terjadi pada iterasi ke II dalam langkah ke Sepuluh Jalan, yakni pengambilan biji dari lubang $A_{3}$ habis di lubang yang sama tanpa ada minimal 1 biji yang mendiami lubang $A_{3}$ sebelumnya. Jumlah biji yang terkumpul pada lubang induk milik pemain A sampai terjadinya Sirkuit Hamilton adalah sebanyak 15 biji. Lebih lanjut akan 
dilakukan dilakukan pencarian sirkuit Hamilton pada permainan congklak dengan 16 lubang seperti pada gambar 5 berikut ini

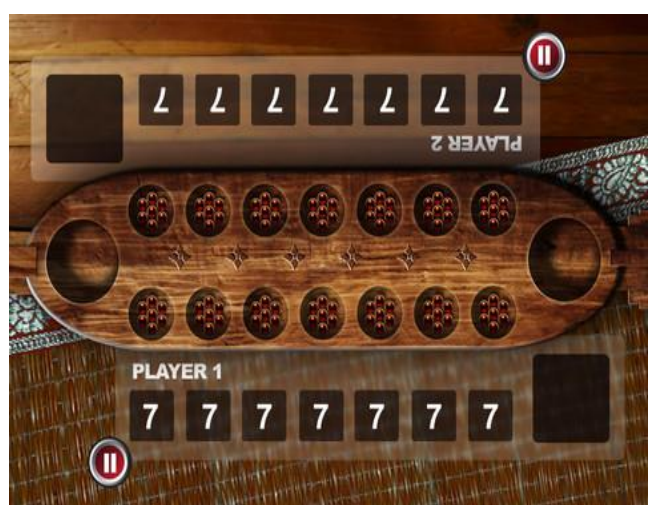

Gambar 5. Congklak dengan 16 Lubang

Pada gambar 5 diatas, terlihat bahwa congklak memiliki 16 lubang dengan rincian 14 lubang kecil dan 2 lubang induk. Masing-masing pemain memiliki 7 lubang kecil dan 1 lubang induk yang berada disebelah kirinya. Agar memudahkan pencarian sirkuit Hamilton pada congklak 16 lubang, maka lubanglubang congklak akan diberi nama sesuai dengan kepemilikan dari pemain A dan B. Penamaan lubang-lubang ini sama seperti congklak dengan 14 lubang yakni $A_{1}, A_{2}, \ldots, A_{7}$ dan $B_{1}, B_{2}, \ldots, B_{7}$. Lubang induk milik pemain A dibari nama lubang induk A dan lubang induk milik pemain B diberi nama lubang induk B. Hal ini dapat dijelaskan dalam gambar 6 sebagai berikut

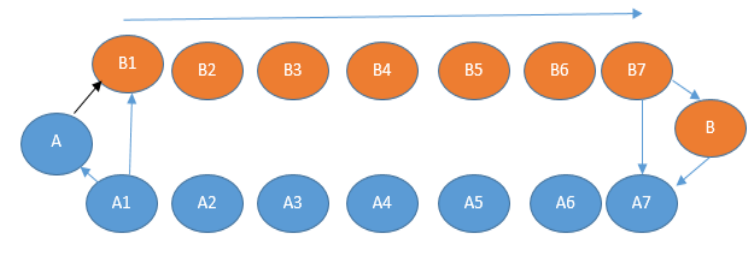

Gambar 6. Pelabelan Congklak 16 Lubang Pada gambar 6 di atas, lubang congklak berwarna biru diasumsikan milik pemain A dan lubang congklak warna oranye diasumsikan milik pemain $B$. Mekanisme permainan congklak 16 lubang ini sama dengan mekanisme permainan congklak dengan 14 lubang, yakni menyebarkan biji-biji congklak yang diambil pada suatu lubang ke seluruh lubang lainnya kecuali pada lubang induk milik lawan. Penyebaran biji-biji congkak ini dilakukan searah jarum jam.

Misalkan kesempatan pertama diberikan kepada pemain A, maka berdasarkan hal tersebut, pemain A berhak memilih biji congklak pada lubang manapun imilikinya untuk disebarkan. Berikut ini beberapa cara yang dapat dilakukan pemain A untuk memilih lubang terjadi Sirkuit Hamilton

Cara I. Memilih Lubang $A_{1}, A_{2}, \ldots, A_{6}$.

Dimanapun diambil biji congklak dari lubang tersebut, terjadi Sirkuit Hamilton. Hal ini karena biji pada lubang $A_{i}$ yang berjumlah 7 buah biji akan habis pada lubang $B_{7-i}, i=1,2,3,4,5,6 \quad$ yang berjumlah 8 biji Berdasarkan hal tersebut 
hanya diperlukan Satu Jalan dan Nol

Iterasi untuk menemukan Sirkuit Hamilton.

\section{Cara II. Memilih lubang A7}

Dengan memilih lubang A7, maka biji congkak akan habis pada lubang induk A, sehingga terjadi Iterasi 1. Langkah awal ini merupakan Satu Jalan. Berdasarkan hal demikian, maka pemain A bebas untuk menentukan lubang yang berisi congklak untuk melanjutkan permainnannya. Dalam hal ini pemain A memiliki 6 pilihan lubang yang dapat dipilih yakni antara $A_{1}, A_{2}, \ldots, A_{6} \quad$ yang masing-masing memiliki 8 biji congklak.

Bagaimanapun pemain A memilih biji pada lubang $A_{i,}, i=1,2,3,4,5,6$ yang memiliki 8 biji, maka biji terakhir akan habis pada lubang $B_{8-i}, i=1,2,3,4,5,6$, dan penyebaran biji dari lubang $B_{8-i}$ akan habis pada lubang $A_{8-i-1}, i=1,2,3,4,5,6$. Hal ini dikarenakan penyebaran biji tidak melewati lubang induk pemain $B$. Pehitungannya akan hal ini disajikan sebagai berikut:

1. Pemilihan lubang $A_{6}$ yang memiliki 8 biji akan habis pada lubang $B_{2}$, sehingga lubang $B_{2}$ kini berisikan 8 biji congklak, dan apabila disebarkan, maka biji dari lubang $B_{2}$ akan habis pada lubang $A_{5}$ dan seterusnya.

2. Pemilihan lubang $A_{5}$ yang memiliki 8 biji akan habis pada lubang $B_{3}$, sehingga lubang $B_{3}$ kini berisikan 8 biji congklak, dan apabila disebarkan, maka biji dari lubang $B_{3}$ akan habis pada lubang $A_{4}$ dan seterusnya.

3. Pemilihan lubang $A_{4}$ yang memiliki 8 biji akan habis pada lubang $B_{4}$, sehingga lubang $B_{4}$ kini berisikan 8 biji congklak, dan apabila disebarkan, maka biji dari lubang $B_{4}$ akan habis pada lubang $A_{3}$ dan seterusnya.

4. Pemilihan lubang $A_{3}$ yang memiliki 8 biji akan habis pada lubang $B_{5}$, sehingga lubang $B_{5}$ kini berisikan 8 biji congklak, dan apabila disebarkan, maka biji dari lubang $B_{5}$ akan habis pada lubang $A_{2}$ dan seterusnya.

5. Pemilihan lubang $A_{2}$ yang memiliki 8 biji akan habis pada lubang $B_{6}$, sehingga lubang $B_{6}$ kini berisikan 8 biji congklak, dan apabila disebarkan, maka biji dari 
lubang $B_{6}$ akan habis pada lubang $A_{1}$ dan seterusnya.

6. Pemilihan lubang $A_{1}$ yang memiliki 8 biji akan habis pada lubang $B_{7}$, sehingga lubang $B_{7}$ kini berisikan 8 biji congklak, dan apabila disebarkan, maka biji dari lubang $B_{7}$ akan habis pada lubang induk $A$ dan artinya terjadi iterasi baru dan harus mengambil lubang baru.

\section{Kesimpulan}

Beberapa kesimpulan yang dari penelitian ini di uraikan sebagai berikut

1. Pada papan congklak 14 lubang, contoh perjalanan menyebarkan biji congklak yang menghasilkan sirkuit Hamilton diberikan, yakni dengan mengambil biji congklak pada lubang $A_{4}$. Dengan mengambil biji congklak pada lubang ini, maka dibutuhkan Dua Iterasi dan Sepuluh Jalan untuk menghasilkan sirkuit Hamilton. Penentuan bentuk umum permainan congklak 14 lubang yang menghasilkan sirkuit Hamilton belum dapat ditentukan dan harus dilakukan pengecekan Trial and Eror karena lubang kecil milik masing-masing pemain sebanyak 6 lubang, namun tiap lubang bersikan 7 biji congklak

2. Pada papan congklak 16 lubang perjalanan menyebarkan biji congklak yang menghasilkan sirkuit Hamilton lebih mudah ditemukan, karena setiap pemain memperoleh 7 lubang kecil dengan tiap lubang berisikan 7 biji congklak. Untuk menghasilkan Sirkuit Hamilton, pemain A dapat memilih lubang manapun antara $A_{1}$ sampai $A_{6}$. Hal ini dikarenakan tipa mengambil biji pada lubang $A_{i}, i=1,2,3,4,5,6$, maka biji congklak akan habis pada lubang $B_{7-i}, i=1,2,3,4,5,6 \quad$ yang berjumlah 8 biji karena mendapat tambahan dari penyebaran biji pada lubang $A_{i}$ tersebut. Cara ini disebut cara I

3. Cara II adalah dengan memilih biji pada lubang A7. Dengan memilih lubang A7 ini akan terjadi iterasi baru karena biji congklak berakhir pada lubang induk. Berdasarkan hal demikian pemain A memiliki 6 pilihan lubang yang dapat dipilih yakni antara $A_{1}, A_{2}, \ldots, A_{6}$ yang masing-masing memiliki 8 biji congklak. Bagaimanapun pemain 
A memilih biji pada lubang $A_{i,}, i=1,2,3,4,5,6$ yang memiliki 8 biji, maka biji terahir akan habis pada lubang $B_{8-i}, i=1,2,3,4,5,6$, dan penyebaran biji dari lubang $B_{8-i}$ akan habis pada lubang $A_{8-i-1}$. Hal ini dikarenakan penyebaran biji tidak melewati lubang induk pemain B.

4. Khusus pemilihan lubang lubang $A_{1}$ yang memiliki 8 biji akan habis pada lubang $B_{7}$, sehingga lubang $B_{7}$ kini berisikan 8 biji congklak, dan apabila disebarkan, maka biji dari lubang $B_{7}$ akan habis pada lubang induk $A$ dan artinya terjadi iterasi baru dan harus mengambil lubang baru. Hal ini memerlukan analisis lebih lanjut

\section{Saran}

Beberapa saran yang diberikan pada paper ini untuk penelitian serupa adalah

1. Agar dapat ditemukan bentuk umum menyebarkan congklak yang menghasilkan sirkuit Hamilton untuk congklak dengan 14 lubang
2. Agar dapat dilakukan analisis lebih lanjut terhadap pemilihan lubang A1 pada cara ke dua yang diawali dengan pemilihan lubang A7

\section{Ucapan Terimakasih}

Ucapan terima kasih penulis sampaikan kepada Perguruan Tinggi Universitas Muhammadiyah Tangerang dan Institut Teknologi Bandung atas segala dukungan sehingga paper ini dapat terselesaikan dan penulis dapat mengikuti seminar nasional pendidikan Ahmad Dahlan di kampus Universitas Ahmad Dahlan pada tanggal 31 Desember 2016.

\section{Pustaka}

Anonim, 2012, "How to play congklak" tersedia di https://zerocrossraptor.wordpress.c om/2012/04/25/congklak-how-toplay/ Diakses tanggal 15 Desember 2016

Galih, 2015 "Permainan tradisional" tersedia

dihttp://grsgalihrestuseptia.blogspo t.co.id/2015/03/permainantradisional-melirik-warisan.html Diakses tanggal 15 Desember 2016

Munir, Rinaldi, 2006, Matematika Diskrit: Diktat kuliah IF, Teknik Informatika STEI: ITB

Wikipedia, 2016, "Permainan congklak". tersedia di http://www.wikipeda/congklak Diakses tanggal 16 Desember 2016

Rukmono, Budi, 2012, "Siklus Hamilton pada langkah ke $\mathrm{K}$ pada permaian tradisional congklak" tersedia di 
www.slideshare.net Diakses

tanggal 16 Desember 2016 